SETBACKS AND SURPRISES

\title{
A scientific basis for restoring fish spawning habitat in the St. Clair and Detroit Rivers of the Laurentian Great Lakes
}

\author{
Bruce A. Manny ${ }^{1,2 \dagger}$, Edward F. Roseman ${ }^{1}$, Gregory Kennedy ${ }^{1}$, James C. Boase ${ }^{3}$, \\ Jaquelyn M. Craig ${ }^{1}$, David H. Bennion ${ }^{1}$, Jennifer Read ${ }^{4}$, Lynn Vaccaro ${ }^{5}$, Justin Chiotti ${ }^{3}$, \\ Richard Drouin 6 , Rosanne Ellison ${ }^{7}$
}

Loss of functional habitat in riverine systems is a global fisheries issue. Few studies, however, describe the decision-making approach taken to abate loss of fish spawning habitat. Numerous habitat restoration efforts are underway and documentation of successful restoration techniques for spawning habitat of desirable fish species in large rivers connecting the Laurentian Great Lakes are reported here. In 2003, to compensate for the loss of fish spawning habitat in the St. Clair and Detroit Rivers that connect the Great Lakes Huron and Erie, an international partnership of state, federal, and academic scientists began restoring fish spawning habitat in both of these rivers. Using an adaptive management approach, we created $1,100 \mathrm{~m}^{2}$ of productive fish spawning habitat near Belle Isle in the Detroit River in $2004 ; 3,300 \mathrm{~m}^{2}$ of fish spawning habitat near Fighting Island in the Detroit River in 2008; and $4,000 \mathrm{~m}^{2}$ of fish spawning habitat in the Middle Channel of the St. Clair River in 2012. Here, we describe the adaptive-feedback management approach that we used to guide our decision making during all phases of spawning habitat restoration, including problem identification, team building, hypothesis development, strategy development, prioritization of physical and biological imperatives, project implementation, habitat construction, monitoring of fish use of the constructed spawning habitats, and communication of research results. Numerous scientific and economic lessons learned from 10 years of planning, building, and assessing fish use of these three fish spawning habitat restoration projects are summarized in this article.

Key words: adaptive management, conceptual design, large rivers

\section{Implications for Practice}

- Restoration of fish spawning habitat in the SCDRS was successful.

- The adaptive management process we followed provided a scientifically defensible framework that allowed our team to reach consensus on informed decisions.

- Application of this framework to restoring habitat allowed learning that improved both the quality and practice of habitat restoration in these large rivers.

- The decision-making framework and adaptive management approach are transferable to other habitat restoration programs. Our experiences emphasize the importance of tailoring project-specific details (such as substrate size, depth, location, materials) to match ecological criteria that maximizes potential benefits (e.g. native fish production) while minimizing negative consequences (e.g. invasive species, infilling).

\section{Introduction}

The world's large rivers are important assets to adjacent human population centers and can be used to promote their unique identity, culture, and economic growth (Hartig et al. 2009;
Pauli 2010). However, degradation of large rivers has occurred globally and has profoundly altered fish communities in those rivers that support local and regional economies (Karr et al. 1985; Dudgeon et al. 2006). Siltation and removal of fish spawning habitats, altered hydrological conditions disconnecting floodplains from river channels, and water pollution have reduced the reproductive capacity of large river systems (Berkman \& Rabini 1987; Mion et al. 1998; Humphries \& Lake 2000). Efforts to abate these perturbations and restore functional fish habitat are underway and include additions of rock and gravel substrates to (1) restore and augment spawning

Author contributions: BAM, EFR, JCB, DHB, JR, LV, RD, RE conceived and designed projects, developed conceptual model and approach; all authors wrote and edited manuscript.

${ }^{1}$ U.S. Geological Survey, Great Lakes Science Center, Ann Arbor, MI, U.S.A. ${ }^{2}$ Address correspondence to B. A. Manny, email bmanny@usgs.gov

${ }^{3}$ U.S. Fish and Wildlife Service, Waterford, MI, U.S.A

${ }^{4}$ University of Michigan Water Center, Ann Arbor, MI, U.S.A.

${ }^{5}$ Michigan Sea Grant, University of Michigan, Ann Arbor, MI, U.S.A.

${ }^{6}$ Ontario Ministry of Natural Resources, London, Ontario Canada

${ }^{7}$ U.S. Environmental Protection Agency, Grosse Ile, MI, U.S.A.

${ }^{\dagger}$ Present address: US Geological Survey, Great Lakes Science Center, 1451 Green Road, Ann Arbor, MI, U.S.A.

Published 2014. This article is a U.S. Government work and is in the public domain in the USA.

doi: $10.1111 /$ rec. 12159 
habitat of lithophilic fishes (e.g. Rhine River, France and Germany, Kuhl 1992; California rivers, Kondolf \& Matthews 1993; Des Prairies River, Quebec, Dumont et al. 2011), (2) reconnect river channels with floodplains (e.g. Phelps et al. in press), and (3) reduce point-source contaminants and watershed-derived nutrients to improve water quality (e.g. Great Lakes, Adler et al. 1993; Mapes et al. in press). Since 1970, water quality has improved in river systems of the United States due to legislation that reduced point-source pollution (Adler et al. 1993). Improved water quality provided opportunities to restore spawning habitat in many large rivers, including the St. Clair-Detroit River System (SCDRS) that connects lakes Huron and Erie, in the central Laurentian Great Lakes (Fig. 1). Historically in the SCDRS, a group of lithophilic fishes including Acipenser fulvescens (lake sturgeon), Sander vitreus (walleye), and Coregonus clupeaformis (lake whitefish), were abundant (Manny et al. 1988). By 1925, overfishing and the removal of more than 46 million $\mathrm{m}^{3}$ of substrates from the Detroit River (Bennion \& Manny 2011), and a like amount of substrates from the St. Clair River, to create deep-draft shipping channels, greatly reduced the amount of spawning habitat and fish populations in these rivers.

Since 2004, restoration of spawning habitat in the SCDRS has been an objective of an international initiative (Manny et al. 2005). A goal of this initiative is to remediate loss of fish habitat and restore degraded fish populations (Manny 2003; Hartig et al. 2009) by restoring natural reproduction of remnant native populations (Kerr et al. 2010; Kerr 2011). A systematic, science-based, adaptive-management protocol (Hondorp et al. 2014) was developed to restore spawning habitat in these rivers. Here, we describe how that scientific approach was developed and implemented in these two rivers.

\section{Methods}

\section{Study Area}

The St. Clair River, Lake St. Clair, and the Detroit River form a waterway, and part of the international boundary, between the United States and Canada (Fig. 1). The waterway connects lakes Huron and Erie and is commonly referred to as the Huron-Erie Corridor (HEC) or, more recently, the SCDRS to better emphasize their localized sense of place. The waterway is a major navigation route and recreational resource of the Great Lakes basin, where more than $\$ 80$ billion in trade takes place annually. As part of the St. Lawrence Seaway, it also links the North American heartland with international ports and includes the second busiest port in America, the Port of Detroit (Roseman et al. 2014). Since 1900, fish habitat in the SCDRS has been greatly reduced by loss of coastal wetlands, shoreline filling and armoring, and shipping channel construction (Manny et al. 1988; Bennion \& Manny 2011).

\section{Adaptive Management Framework}

Our approach to habitat restoration followed a science-based, adaptive management framework (Walters \& Hilborn 1978;
Krueger \& Decker 1993) that guided decision making, hypothesis development, strategic implementation, and monitoring (Fig. 2). This framework provided a structured, iterative process for experimentation, monitoring, and decision making that reduced uncertainty and advanced our understanding of the ecosystem.

Identify Problem. The SCDRS is a highly altered and degraded ecosystem that offers unique challenges for restoration. At the end of the 19th century, it supported several valuable fisheries, including A. fulvescens (Manny \& Mohr 2013) and C. clupeaformis (Roseman et al. 2008). However, decades of habitat alteration (Manny 2003; Bennion \& Manny 2011), water and sediment pollution (Hartig et al. 2009), and overharvest greatly reduced populations in these rivers (Tody 1974; Roseman et al. 2008). Millions of tons of limestone bedrock, cobble, and gravel were removed from the SCDRS to build the cities of Detroit, Michigan and Windsor, Ontario and to create over $100 \mathrm{~km}$ of navigation channels (Larson 1981). Those gravel and rock substrates were spawning and nursery habitat for $A$. fulvescens, $S$. vitreus, C. clupeaformis, and numerous other native fishes (Goodyear et al. 1982). Loss of these spawning habitats reduced fish populations and resulted in portions of the SCDRS being designated Great Lakes Areas of Concern (AOCs), owing to loss of fish habitat and degradation of fish populations (Manny 2003). Particularly damaging was the Livingstone Channel project, in the early 1900s. This $19.3 \mathrm{~km}$ shipping channel was cut through a limestone bedrock sill near the mouth of the Detroit River, with a minimum width and depth of $244 \mathrm{~m}$ and $6.4 \mathrm{~m}$, respectively, and removed $46,200,000 \mathrm{~m}^{3}$ of substrate (Bennion \& Manny 2011). The Livingstone Channel project greatly altered the river's hydrology, destroyed many hectares of fish spawning grounds in the river (Manny et al. 1988), and coincided with cessation of spawning by the economically valuable $C$. clupeaformis in the Detroit River (Bennion \& Manny 2011).

Assessing Contemporary Status. Inventory and assessment of the current biological and physical conditions are necessary to make informed decisions about restoration and management of large rivers (Hartig et al. 2009; Hondorp et al. 2014). Pre-construction data on the abundance and distributions of extant fish species and their habitats provide a baseline for comparisons with post-construction monitoring, and reveal their current status. These data come from ongoing agency monitoring programs in the SCDRS that include fish community inventories (Goodyear et al. 1982; Thomas \& Willis 2013; Francis et al. 2014), species-specific fish population monitoring (Nichols et al. 2003; Thomas \& Haas 2004; Manny et al. 2014), and physical habitat assessments (Bennion \& Manny 2014).

Developing Hypotheses. Our restoration projects focus on restoration of native, broadcast spawning fish populations and their reproductive habitats. They are designed to benefit recreationally and commercially important fishes (such as $S$. vitreus and C. clupeaformis) and to recover and sustain State of 


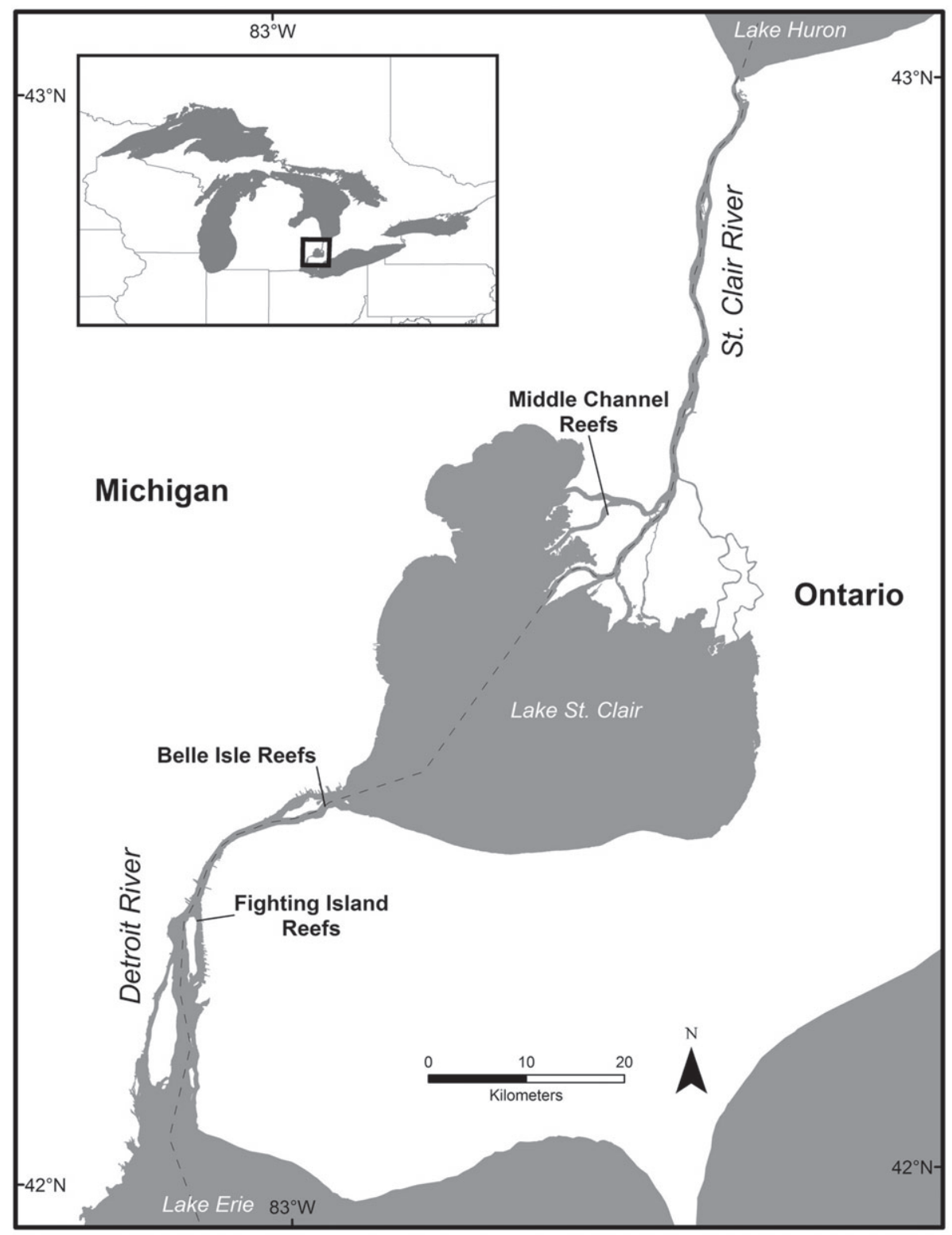

Figure 1. Overview of the St. Clair — Detroit River system, showing the location of three fish spawning habitat restoration projects.

Michigan- and Province of Ontario's- threatened and endangered fishes (such as A. fulvescens and Noturus stigmosus [northern madtom]). Scientific evaluation of our hypotheses is accomplished by comparing pre- and post-construction egg deposition densities and longer term changes in fish population abundances from our pre-construction assessments and long-term evaluations.

Building Consensus. Our research and restoration efforts have benefited from multi-jurisdictional, international cooperation, and support for habitat restoration. In 2002, the HEC Initiative (www.huron-erie.org) brought together an international, multi-disciplinary partnership including federal, tribal, state, provincial, local, and non-governmental participants who collaborate to restore fish populations and their habitats in the SCDRS (Manny et al. 2005). The Initiative operates under a structured governance to conduct research related to a common agenda (Karr 1967; Kania \& Kramer 2011). The governance structure supports mutually beneficial activities through coordinated collaboration rather than competition for resources or duplication of results, timely communication within the team and with external audiences to increase scientific productivity (Lindenmayer \& Likens 2010), and celebrate successes. A steering committee was formed in 2013 to determine fishery research strategies in these waters, establish collaborations, and pursue funding opportunities, all by consensus. It is comprised of partners who conduct research, manage, and protect economically valuable resources in these rivers as well as organizations 


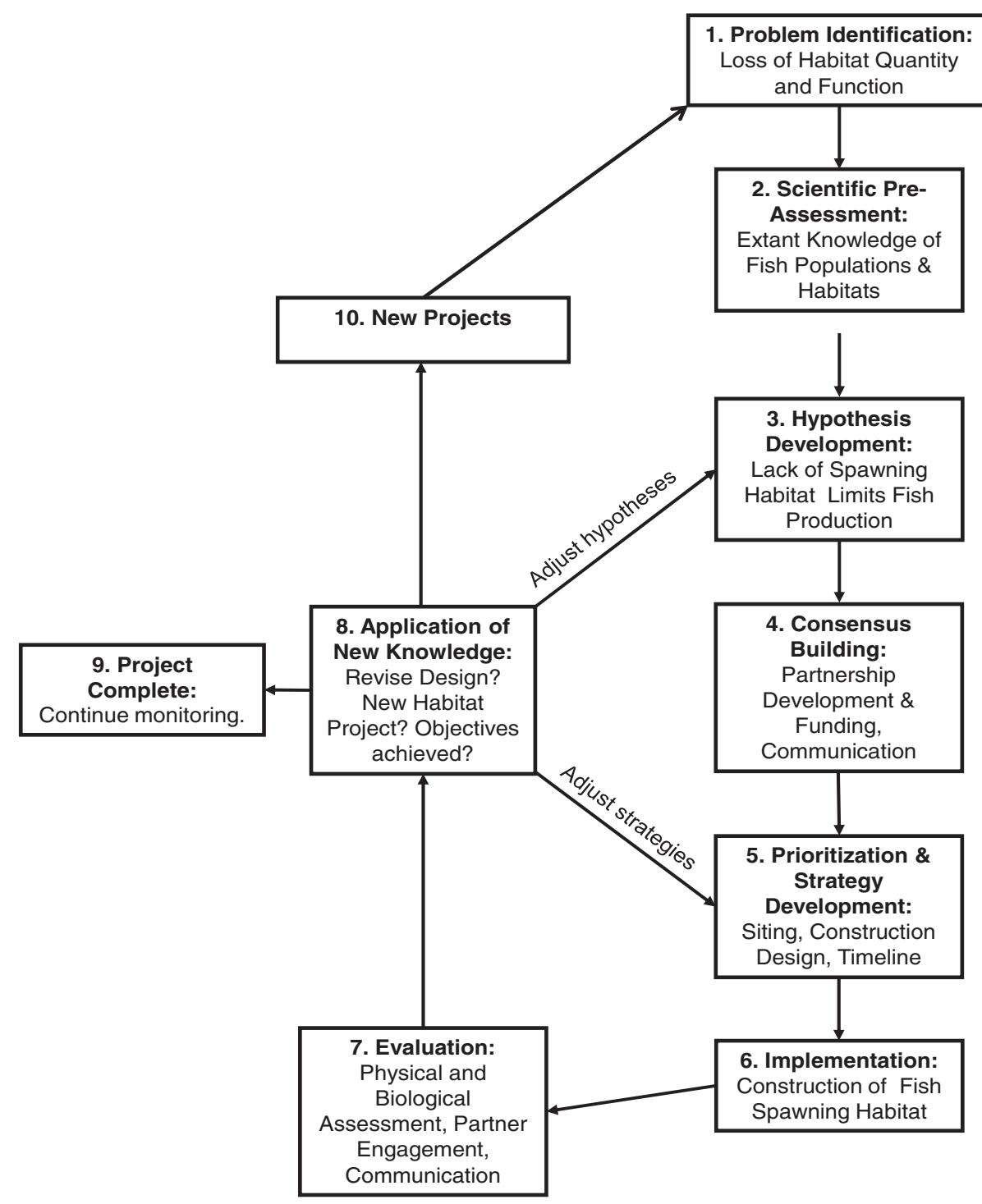

Figure 2. Conceptual diagram of the adaptive management approach to fish spawning restoration employed in the St. Clair and Detroit Rivers.

that provide public education opportunities. The group meets annually to assess research needs, identify emerging issues, and determine next steps in aquatic habitat restoration.

Prioritizing Restoration Actions. Restoration priorities are determined by consensus of the international SCDRS Initiative, and are based on scientific principles and available research results. To select candidate sites for reef restoration, we used a biophysical model (Bennion \& Manny 2014) to determine where water depth and water velocity in the two rivers are theoretically optimal for spawning by desirable, native, and lithophilic fish species.

Implementation. Project implementation follows an iterative series of steps, with feedback and adjustment opportunities built in through on-going consultation and an adaptive management approach (Fig. 2).

\section{Site Assessment and Reef Siting}

Proposed restoration areas are carefully studied to inform the placement and design of spawning habitat structures. Side scan sonar, underwater video, and other survey tools are used to measure the bathymetry and characterize sediments at a proposed area. This information is used to locate the reef in erosional areas with smooth, hard-pan clay or bedrock bottom, where there is no evidence of mobile bedforms such as sand ripples, and little existing rock-rubble habitat. Spawning beds are built at water depths deeper than the limit of light penetration to prevent plant growth that can deter spawning by some lithophilic fishes (Johnson et al. 2006). We use an Acoustic Doppler Current Profiler (ADCP) to evaluate flow patterns across the candidate area of river bottom to select a site with steady, high-velocity water $(>0.7 \mathrm{~m} / \mathrm{s})$ flows. SCUBA divers survey the area to refine descriptions and mapping of river 
bottom sediments and ensure that no sediments are accumulating at the site (Rosgen 1996). Finally, the team considers historical dredging records, upstream tributaries and changes in the geomorphology of the river, and consults with other hydrologists working in the system to identify known sources of sediment in the immediate upstream area of candidate sites. This consultation can expose other potential problems, such as industrial and municipal waste water outfalls, or dredged channels.

\section{Project Design and Engineering}

Project dimensions are optimized for a particular location, depending on physical conditions as well as human use of the shoreline and river channel. Size of the reef is designed to be commensurate with the size of the river system, enabling target fish species to quickly locate the new habitat. Spawning beds are typically long and narrow, oriented parallel to water flow, with relatively low vertical relief ( $<0.61 \mathrm{~m}$ for SCDRS projects) to avoid cross-sectional impedance of water flow that causes sediments to deposit and fill interstices within the reef.

A variety of materials have been used to construct spawning habitat as the team tested hypotheses related to species preference over the first three projects. Initially the team tested three distinctive types of substrate based on literature review and knowledge of what the most sensitive target species were using elsewhere in the SCDRS system or similar systems in the Great Lakes region. These were $10-25 \mathrm{~cm}$ cobblestones, quarried limestone $10-20 \mathrm{~cm}$ in diameter, and coal cinders approximately $7 \mathrm{~cm}$ in diameter. Reefs composed of these three materials and mixtures of the materials were tested in three locations. Post-construction assessment determined no statistically strong preference for any of these treatments (Roseman et al. 2011). Given concerns about potential use of reefs by invasive species, rocks smaller than $10 \mathrm{~cm}$ are avoided to prevent spawning use by Petromyzon marinus (sea lamprey) and rocks larger than $25 \mathrm{~cm}$ are not used to reduce the chance that Neogobius melanostomus (round goby) will colonize to prey on native fish eggs. Over time, the team has determined that $10-20 \mathrm{~cm}$ quarried limestone is both the most effective and least expensive material to use. Once project siting and design parameters are selected, professional engineers develop construction diagrams and specifications, which often involves an iterative process, as new issues surface.

\section{Project Permitting and Construction}

For our projects in the U.S. and Canadian waters of Great Lakes connecting channels, an extensive consultation and permitting process is required. This includes obtaining state, provincial, and federal permits needed to place structures in the river. Permit applications require written permission from shoreline property owners, a public comment process, and a review by the State Historic Preservation Office. In addition, because these waters are governed by the 1909 Boundary Waters Treaty, consultation with Canadian federal authorities on potential impact to conveyance is required. Depending on the origin of the construction funds, a formal compliance process under the National
Environmental Protection Act may also be required. When possible, the team anticipates such concerns and consults with stakeholders prior to permitting. A marine construction contractor is selected through a competitive bidding process and bidders must propose the most suitable rock placement methods and rock sources. Rock for the case study projects was placed either by a GPS-guided clam and crane mounted on a barge, or by dumping and spreading the rock with a dump barge and drag. Contractors can often identify small changes to the project design that allow more cost effective rock sourcing or placement. Projects involving complex reef shapes and multiple rock types are more expensive. Some economy can be achieved through larger or bundled projects that minimize costs of transporting equipment to the site. Scientific surveys of the river bottom before and after construction ensure that rock placement is uniform and precise, allows water to flow smoothly over the habitat, and facilitates scientific monitoring of the constructed habitat.

Evaluation. Scientific assessment of constructed reefs provides information about fish use of the reefs that is integral to the adaptive management process we use to determine if restoration goals and objectives are being met (Walters \& Hilborn 1978). We conduct a minimum of two years (Belle Isle reef now has $\sim 10$ years) of intensive, post-construction, scientific monitoring at each habitat restoration site (e.g. Roseman et al. 2011), and changes in reef structure or performance. Because fish species that we want to support have long maturity schedules and life cycles, population-level responses by adults can only be assessed by long-term monitoring that measures a short list of indicators describing a wide range of fish population and habitat metrics (Karr 1967; Oakley et al. 2003). Post-construction assessments are designed with defensible statistical rigor, typically using a before-after-control concept (Scheiner \& Gurevitch 1993) that compares post-construction results statistically with pre-construction data. We also survey upstream and downstream of the constructed reefs, to measure localized impacts of reefs on fish spawning activity, egg density and distribution, and larval fish production on the restored habitats. Adult fish populations are sampled using gillnets and setlines (Thomas \& Haas 2004). Long-term assessment of the physical changes in the constructed reefs, particularly in-filling with sand and/or silts, is done by a team of SCUBA divers, to detect changes in the reef structure (i.e. sediment infilling) and biological changes on the reefs (i.e. colonization by fish egg predators) that are detrimental to fish egg deposition, hatching, and survival.

Application of New Knowledge. Based on the information collected from post-construction monitoring, we have adapted our strategies and techniques to improve both the quality of habitat and the adaptive management process we use to guide decision making. Examples of these lessons learned are described below in our case studies.

\section{Case studies in the SCDRS}

Pre-construction assessment at the Belle Isle reef began in 2003 with measurements of water velocity throughout the water 
Table 1. Numbers of reef beds, sizes, orientation, and percentage of channel width for each of the three fish spawning reefs constructed in the Detroit and St. Clair Rivers in efforts to restore functional fish spawning habitat.

\begin{tabular}{lccccc}
\hline Reef & No. Reef Beds & Ind. Reef Size & Total Size & Orientation to Flow & Reef Width \\
\hline Belle Isle & 3 & $380 \mathrm{~m}^{2}$ & $1100 \mathrm{~m}^{2}$ & With Channel Width & $15 \mathrm{~m}$ \\
Fighting Island & 12 & $275 \mathrm{~m}^{2}$ & $3300 \mathrm{~m}^{2}$ & Across & $176 \mathrm{~m}$ \\
Middle Channel & 9 & $450 \mathrm{~m}^{2}$ & $4000 \mathrm{~m}^{2}$ & Across & $134 \mathrm{~m}$ \\
\hline
\end{tabular}

column and assessment of the composition of river bottom substrates at Belle Isle near the head of the Detroit River (Fig. 1; Manny 2006) to determine whether the physical habitat met the needs of lithophilic spawning fish. This restoration site was chosen for its deep water, high water velocity, and good water quality, as well as its proximity to historic spawning grounds (Goodyear et al. 1982). Water velocity throughout the water column was measured with a Gurley Current Meter and a Sontek M9 ADCP water current meter. River substrates in the area were investigated using side-scan sonar, underwater videography (Manny \& Kennedy 2002), and SCUBA divers.

In 2004, we constructed three fish spawning beds near the southeast shore of Belle Isle (Table 1; Fig. 1). These beds were constructed parallel to the direction of river flow. Total area of created fish spawning habitat at the three reefs equaled $1,100 \mathrm{~m}^{2}$ of river bottom (Manny 2006). Substrates used to construct the habitat included materials used elsewhere within the Great Lakes Basin for reproduction by lake sturgeon: e.g. broken limestone, like that placed in Wisconsin rivers (Bruch \& Binkowski 2002); rounded, igneous, cobble like that found at the head of the St. Clair River (Manny \& Kennedy 2002); and coal-cinder material like that found in the North Channel of the St Clair River, near Algonac, Michigan (Nichols et al. 2003; Thomas \& Haas 2004). Large anchor stone ( $>0.5 \mathrm{~m}$ diameter) was placed on the upstream edge of the reef to abate ice scour of reefs. Unfortunately, post-construction assessments by SCUBA divers revealed that sediment accumulated immediately downstream of the anchor stones, filling interstitial spaces in the spawning habitat. The team therefore determined to avoid using anchor stone upstream of reef beds because it reduces current velocity and allows silt and sediment to settle out of the water column onto the spawning reef. Post-construction fisheries assessments conducted since 2004 have revealed that 14 species of fish, including $S$. vitreus and $C$. clupeaformis, but no A. fulvescens, spawned on the man-made reefs at Belle Isle (Manny 2006).

In $2008,3,300 \mathrm{~m}^{2}$ of new fish spawning habitat was constructed at Fighting Island in the Detroit River (Table 1; Fig. 1) employing a "no-miss" design, where reef beds spanned the entire channel width. This site was within the known range of adult A. fulvescens (Manny \& Kennedy 2002). Changes to habitat design and fisheries assessment techniques employed at Fighting Island, in addition to spanning the entire channel, included constructing the reefs with two sizes of broken limestone, rounded igneous rock, or a mixture of equal parts of those. Repetition of the four treatments permitted statistical analyses of fish spawning results on the substrates (Roseman et al. 2011). The anchor stones were placed downstream of the reef beds to provide low-velocity, resting habitat for migrating fishes.

These reefs were promptly used for reproduction by $A$. fulvescens, S. vitreus, and C. clupeaformis (Roseman et al. 2011; Bouckaert et al. in press). Underwater video and SCUBA assessments of the constructed reef in subsequent years showed that reef beds on the east side of the channel, where velocities are slower, had filled in with fine sediments. Spawning habitat on the west side of the channel, where velocities were faster $\left(>0.7 \mathrm{~m} \mathrm{sec}^{-1}\right)$, remained viable with no evidence of infilling. Spawning beds there were expanded by another $3,300 \mathrm{~m}^{2}$ in 2013 and the reef continues to be used for spawning by desirable fishes (USGS unpublished data).

In 2012, our third fish spawning reef was constructed in the Middle Channel of the St. Clair River (Table 1; Fig 1), creating $4,000 \mathrm{~m}^{2}$ of fish spawning habitat within an area frequented by adult $A$. fulvescens (Manny \& Kennedy 2002). Because design and construction for this reef was already underway before infilling was fully documented at Fighting Island, the Middle Channel reef followed the same materials and cross-channel "no-miss" design used at Fighting Island. A. fulvescens spawned on reef beds at Middle Channel during construction in 2012 and again in 2013. Large stones ( $>0.35 \mathrm{~m}$ in diameter) were also placed in a random pattern directly downstream of that reef to provide a current-break for fishes, similar to the design at Fighting Island. Post-construction assessments of the Middle Channel reef using SCUBA divers and underwater video showed that the reef beds on the southeast side of the channel were largely covered with sediment, similar to Fighting Island.

Sediment infilling of some of the spawning reef beds constructed at the Fighting Island and Middle Channel projects taught us that small differences in reef placement within a channel can influence infilling with sediment and reef performance. To minimize the potential for infilling at future reef restoration sites and to inform our selection criteria for future reef construction, we invited experts in river hydrology and geomorphology to join the team and provide insight on sediment movement and water velocity patterns. Sites selected for future reef restoration have lower potential for infilling, due to the team's ability to identify and avoid depositional zones as a result of this consultation. Our habitat restoration projects presently consist of one type of substrate material $(10-20 \mathrm{~cm}$ broken limestone), placed in a rectangular shape longer than they are wide (e.g. $30 \times 180 \mathrm{~m}$ ), oriented parallel to flow, and designed and located to minimize infilling. 


\section{Discussion}

Our 10 years of experience in constructing and assessing fish use of reefs in two large rivers revealed that knowledge of river hydrodynamics and sediment transport is essential for locating where to construct spawning habitat. Secondly, knowledge of river hydrodynamics and fish behavior, including factors that govern choices made by the target species of where, and on what substrates they spawn, are essential to increasing usable habitat in the river. River hydrodynamics are also important in selecting sites that remain free of sediments that can fill interstices between rock-rubble substrates. These interstitial spaces must be present to protect fish eggs from predation and dislodgement by river currents during their period of incubation on the spawning substrates. Without complete knowledge of physical habitat and biological requirements of target species during their spawning period in the river, success in constructing long-lasting, productive habitat will be limited.

\section{Acknowledgments}

The authors thank the numerous technicians and students who worked on these projects. The findings and conclusions in this article are those of the authors and do not necessarily represent the views of the U.S. Fish \& Wildlife Service. Use of trade names is for descriptive purposes and does not imply endorsement by USGS. This is contribution number 1886 of the U.S.G.S. Great Lakes Science Center.

\section{LITERATURE CITED}

Adler RW, Landman JC, Cameron DM (1993) The clean water act 20 years later. Island Press, Washington, D.C.

Bennion DH, Manny BA (2011) Construction of shipping channels in the Detroit River: history and environmental consequences. Scientific Investigations Report 2011-5122. U.S. Geological Survey, Ann Arbor, Michigan

Bennion DH, Manny BA (2014) A model to locate potential areas for lake sturgeon spawning habitat construction in the St. Clair-Detroit River System. Journal of Great Lakes Research 40:43-51

Berkman HE, Rabini CF (1987) Effect of siltation on stream fish communities. Environmental Biology of Fishes 18:285-294

Bouckaert EK, Auer NA, Roseman EF, Boase J (2014) Verifying success of artificial reefs in the Huron-Erie Corridor for lake sturgeon. Journal of Applied Ichthyology (In press)

Bruch RM, Binkowski FP (2002) Spawning behavior of lake sturgeon (Acipenser fulvescens). Journal of Applied Ichthyology 18:570-579

Dudgeon D, Arthington AH, Gessner MO, Kawabata ZI, Knowler DJ, Lévêque C, et al. (2006) Freshwater biodiversity: importance, threats, status and conservation challenges. Biological Reviews 81:163-182

Dumont P, D'Amours J, Thibodeau S, Dubuc N, Verdon R, Garceau S, Bilodeau P, Mailhot Y, Fortin R (2011) Effects of the development of a newly created spawning ground in the Des Prairies River (Quebec, Canada) on the reproductive success of lake sturgeon (Acipenser fulvescens). Journal of Applied Ichthyology 27:394-404

Francis J, Chiotti JA, Boase J, Thomas M, Manny B, Roseman EF (2014) An assessment of the nearshore fish communities in the St. Clair-Detroit River System. Journal of Great Lakes Research 40:52-61

Goodyear CD, Edsall TA, Demsey DM, Moss GD, Polanski PE (1982) Atlas of the spawning and nursery areas of Great Lakes fishes. FWS/OBS-82/52, Vols.1-14. U.S. Fish and Wildlife Service, Washington, D.C.

Hartig JH, Zarull MA, Ciborowski J, Gannon J, Wilke E, Norwood G, Vincent A (2009) Long-term ecosystem monitoring and assessment of the Detroit
River and western Lake Erie. Environmental Monitoring and Assessment $158: 87-104$

Hondorp DW, Roseman EF, Manny BA, Seelbach PW, Newman KR, Strach RM (2014) An ecological basis for fish habitat restoration in the Huron-Erie Corridor. Journal of Great Lakes Research 40:23-30

Humphries P, Lake PS (2000) Fish larvae and the management of regulated rivers. Regulated Rivers: Research and Management 16:421-432

Johnson JH, LaPan SR, Klindt RM, Schiavone A (2006) Lake sturgeon spawning on artificial habitat in the St. Lawrence River. Journal of Applied Ichthyology 22:465-470

Kania J, Kramer M (2011) Collective impact. Stanford Social Innovation Review Winter 2011:36-41

Karr JR (1967) Biological monitoring and environmental assessment: a conceptual framework. Environmental Management 11:249-256

Karr JR, Toth LA, Dudley DR (1985) Fish communities of Midwestern rivers: a history of degradation. BioScience 35:90-95

Kerr SJ (2011) Documentation of lake sturgeon habitat in the Ontario waters of the Great Lakes drainage basin. Ontario Ministry of Natural Resources, Peterborough, UK

Kerr SJ, Davison MJ, Funnell E (2010) A review of lake sturgeon habitat requirements and strategies to protect and enhance sturgeon habitat. Ontario Ministry of Natural Resources, Peterborough, UK

Kondolf GM, Matthews WVG (1993) Management of coarse sediment in regulated rivers of California. Report No. 80. University of California Water Resources Center, Davis, California

Krueger CC, Decker DJ (1993) The process of fisheries management. Pages 33-54. In: Kohler CC, Hubert WA (eds) Inland Fisheries Management in North America. American Fisheries Society, Bethesda, Maryland

Kuhl D (1992) 14 years of artificial grain feeding in the Rhine downstream of the barrage Iffezheim. Pages 1121-1129. In: Larsen P, Eisenhauer N (eds) Proceedings of the $5^{\text {th }}$ International Symposium on River Sedimentation. Karlsruhe, Germany

Larson J (1981) Essayons: A history of the Detroit District U.S. Army Corps of Engineers. U.S. Army Corps of Engineers, Detroit, Michigan

Lindenmayer DR, Likens GE (2010) The science and application of ecological monitoring. Biological Conservation 143:1317-1328

Manny BA (2003) Setting priorities for conserving and rehabilitating Detroit River habitats. Pages 121-139. In: Hartig JH (ed) Honoring our Detroit River, caring for our home. Cranbrook Institute of Science, Bloomfield Hills, Michigan

Manny BA (2006) Monitoring element of the Belle Isle/Detroit River sturgeon habitat restoration, monitoring, and education project. Research completion report to Michigan Sea Grant Program, Ann Arbor, Michigan

Manny BA, Kennedy GW (2002) Known lake sturgeon (Acipenser fulvescens) spawning habitat in the channel between Lakes Huron and Erie in the Laurentian Great Lakes. Journal of Applied Ichthyology 18:486-490

Manny BA, Mohr L (2013) Rehabilitation of lake sturgeon in the Great Lakes. Pages 495-532. In: Taylor WW, Lynch AJ, Leonard NJ (eds) Great Lakes Fisheries Policy and Management. Michigan State University Press, East Lansing, Michigan

Manny BA, Edsall TA, Jaworski E (1988) The Detroit River, Michigan. An ecological profile. Biological Report 88. U.S. Fish and Wildlife Service, Ann Arbor, Michigan

Manny BA, Daley BA, Boase JC, Horne AN, Chiotti JA (2014) Occurrence, habitat, and movements of the endangered northern madtom (Noturus stigmosus) in the Detroit River, 2003-2011. Journal of Great Lakes Research 40(Supplement 2):118-124

Manny BA, Carl LM, Morrison SS, Nichols SJ, Roseman EF, Riley SC (2005) The U.S. geological survey Huron-Erie Corridor Initiative. Pages 92-97. In: Eedy R, Hartig J, Bristol C, Coulter M, Mabee T, Ciborowski J (eds) State of the Strait: monitoring for sound management. Occasional Publication No. 4 Great Lakes Institute for Environmental Research, University of Windsor, Windsor, Ontario, Canada

Mapes RL, DuFour MR, Pritt JJ, Mayer CM (2014) Larval fish assemblage recovery: a reflection of environmental change in a large degraded river. Restoration Ecology, DOI: 10.1111/rec.12138 
Mion JB, Stein RA, Marschall EA (1998) River discharge drives survival of larval walleye. Ecological Applications 8:88-103

Nichols SJ, Kennedy G, Crawford E, Allen J, French J III, Black G, et al. (2003) Assessment of lake sturgeon (Acipenser fulvescens) spawning efforts in the lower St. Clair River. Journal of Great Lakes Research 29:383-391

Oakley KL, Thomas LP, Fancy SG (2003) Guidelines for long-term monitoring protocols. Wildlife Society Bulletin 31:1000-1003

Pauli G (2010) The Blue Economy: 10 years - 100 innovations - 100 million jobs. Report to the Club of Rome. Paradigm Publications, Taos, New Mexico

Phelps QE, Tripp SJ, Herzog DP, Garvey JE (2014) Temporary connectivity: the relative benefits of large river floodplain inundation in the lower Mississippi River. Restoration Ecology, DOI: 10.1111/rec.12119

Roseman EF, Kennedy G, Manny BA, Boase J, McFee J (2008) Life history characteristics of a recovering lake whitefish Coregonus clupeaformis stock in the Detroit River, North America. Advances in Limnology 63: $477-501$

Roseman EF, Manny BA, Boase J, Child M, Kennedy G, Craig J, Soper K, Drouin R (2011) Lake sturgeon response to a spawning reef constructed in the Detroit River. Journal of Applied Ichthyology 27(Supplement 2): $66-76$

Coordinating Editor: Robin DeBruyne
Roseman EF, Thompson PA, Farrell JM, Mandrak NE, Stepien CA (2014) Conservation and management of fisheries and aquatic communities in Great Lakes connecting channels. Journal of Great Lakes Research 40(Supplement 2): $1-6$

Rosgen D (1996) Applied River Morphology. Wildland Hydrology, Pagosa Springs, Colorado

Scheiner SM, Gurevitch J (1993) Design and analysis of ecological experiments. Chapman \& Hall, New York

Thomas M, Haas R (2004) Abundance, age structure, and spatial distribution of lake sturgeon (Acipenser fulvescens) in the St. Clair System. Fisheries research report 2076. Michigan Department of Natural Resources, Lansing, Michigan

Thomas MV, Willis T (2013) Status of the fisheries in Michigan waters of Lake Erie and Lake St. Clair, 2012. Annual report prepared for the Great Lakes Fishery Commission, Lake Erie Committee. Michigan Department of Natural Resources, Mt. Clemens, Michigan

Tody WH (1974) Whitefish, sturgeon, and the early Michigan commercial fishery. Management Report 6, Michigan fisheries centennial report 1873-1973. Michigan Department of Natural Resources, Lansing, 45-60

Walters CJ, Hilborn R (1978) Ecological optimization and adaptive management. Annual Review of Ecology and Systematics 9:157-188

Received: 6 June, 2014; First decision: 4 August, 2014; Revised: 13 October, 2014; Accepted: 13 October, 2014; First published online: 5 December, 2014 